\title{
Complexo Eólico Chapada do Piauí I: Benefícios Sociais e Impactos Ambientais no Município de Marcolândia, Estado do Piauí
}

\author{
Chapada Do Piauí I Wind Complex: Social Benefits and Environmental Impacts \\ in the Municipality of Marcolândia, State of Piauí
}

\section{Complejo Eólico Chapada do Piauí I: Beneficios Sociales e Impactos Ambientales en el Municipio de Marcolândia, Estado de Piauí}

\author{
Jaerle Rodrigues Câmpelo ${ }^{1}$ \\ Emanuel Lindemberg Silva Albuquerque ${ }^{2}$ \\ José Maria Marques de Melo Filho ${ }^{3}$
}

\begin{abstract}
RESUMO: A busca por novas alternativas de geração de energia proveniente de fontes renováveis e limpas visa mitigar os impactos socioambientais provocados pela utilização dos combustíveis fósseis. Com o estabelecimento desse cenário, a energia é́lica obtida por meio do "movimento dos ventos" ganhou bastante destaque, e no Brasil, sobretudo no Nordeste, em razão de suas características geográficas, encontrou condições favoráveis para seu desenvolvimento. Neste sentido, o presente trabalho objetivou analisar, de forma integrada, os impactos socioambientais oriundos da implantação do Complexo Eólico Chapada do Piauí I, nas comunidades localizadas no município de Marcolândia, na perspectiva de correlacionar as vantagens da geração de energia eólica com os conflitos ambientais e sociais que são identificados e materializados in loco. A implementação do Complexo provocou efêmero dinamismo econômico local e transformações na paisagem. A partir desta perspectiva, almeja-se que a análise em pauta possa contribuir com outros estudos que se propõem a discutir a transformação da paisagem local a partir da perspectiva socioambiental, tendo como pano de fundo a implantação de tecnologias de exploração eólica como matriz energética.
\end{abstract}

PALAVRAS-CHAVE: Energias renováveis. Energia eólica. Impactos socioambientais.

ABSTRACT: The search for new energy generation alternatives from renewable and clean sources aims to mitigate the socio-environmental impacts caused by the use of fossil fuels. With the establishment of this scenario, wind energy, which is obtained through the "wind movement", has gained a lot of prominence. Due to Brazil's geographical characteristics, wind energy has found favorable conditions for its development, especially in the Northeastern region. Therefore, this study aimed to analyze, in an integrated way, the social and environmental impacts resulting from the

\footnotetext{
${ }^{1}$ Universidade Federal do Espírito Santo- UFES. Av. Fernando Ferrari, 514 - Goiabeiras, Vitória - ES|CEP 29075-910 - E -mail: jaerlec@outlook.com.

${ }^{2}$ Universidade Federal do Piauí - Campus Universitário Ministro Petrônio Portella - Ininga, Teresina - PI, 64049-550 - E-mail: lindemberg@ufpi.edu.br.

${ }^{3}$ Universidade Federal do Paraná - UFPR. Av. Cel. Francisco H dos Santos, 100 - Ed. João José Bigarella - 10 andar - sala 108, Jardim das Américas, Curitiba, CEP: 81531-980. E-mail: josemarquesprofgeo@gmail.com.
} 
implementation of the Chapada do Piaui I Wind Complex in the communities located in the municipality of Marcolândia, State of Piauí, in order to correlate the advantages of wind power generation with the environmental and social conflicts that are identified and verified on-site. The implementation of the complex has caused ephemeral local economic dynamism and transformation in the landscape of the municipality. From that perspective, it is intended that the analysis in question can contribute to other studies that propose to discuss the transformation of the local landscape on the socio-environmental perspective, having as a background the implementation of wind energy technologies as an energy matrix.

KEYWORDS: Renewable energy. Wind energy. Socio-environmental impacts.

RESUMEN: La búsqueda por nuevas formas de generación de energía provenientes de fuentes renovables y limpias ha pretendido mitigar los impactos socioambientales producidos por el uso de combustibles fósiles. Bajo este escenario, la energía eólica obtenida por medio del "movimiento de los vientos" se ha destacado en gran medida en países como Brasil, especialmente en el nordeste, donde gracias a las características y condiciones geográficas que posee, se ha logrado implementar adecuadamente este tipo de tecnologías. En este sentido, el presente trabajo tiene por objetivo analizar, de manera integral, los impactos socioambientales provocados por la implantación del Complejo Eólico Chapada do Piauí I en las comunidades localizadas en el municipio de Marcolândia correlacionando las ventajas que trae la generación de energía eólica con los conflictos ambientales y sociales identificados allí; considerando que su implementación ha provocado un efímero dinamismo económico local así como transformaciones en su paisaje. Con base en lo anterior, se espera que el presente análisis contribuya con otros estudios que se proponen discutir la transformación del paisaje local a partir de una perspectiva socioambiental tomando como punto de partida la implementación de tecnologías de explotación eólica como matriz energética.

PALABRAS-CLAVE: Energía renovable. Energía eólica. Impactos socioambientales.

\section{INTRODUÇÃO}

Ao considerar a questão socioambiental referente à geração de energia, menciona-se que nas últimas décadas surgiram fontes alternativas conhecidas e tidas como energia verde ou energia limpa, com o propósito de mitigar o impacto do consumo de energia procedente de combustíveis fósseis, e assim contribuir com o equilíbrio ambiental do planeta (CÂMPELO et al., 2017).

Neste ínterim, a preocupação crescente com as questões e os problemas ambientais tomou impulso ainda maior em todo o mundo em prol do desenvolvimento sustentável, pois este contempla a tríade sociedade, economia e meio ambiente. Neste sentido, Lopez (2012) apresenta uma perspectiva interessante para este conceito, mencionando que é aquele que atende as necessidades do presente sem comprometer o futuro das próximas gerações.

É importante evidenciar que o desenvolvimento de energia sustentável, a exemplo da geração de energia eólica, em tese não deveria ameaçar os ecossistemas e nem colocar em risco a qualidade de vida humana, visando um futuro energético mais adequado e com o intuito de melhorar o bem-estar social (FERREIRA, 2011; JABER, 2013). 
Dessa forma, a progressiva substituição de combustíveis fósseis por fontes renováveis de energia tem como objetivo a concretização de um cenário futuro de baixa emissão de gases potencializadores do efeito estufa, bem como de mitigação dos efeitos das mudanças climáticas, na perspectiva de encontrar tecnologias de geração de energia que ofereçam segurança energética ao longo prazo, bem como preços acessíveis e baixos impactos ambientais (SIMAS; PACCA, 2013).

Dentre as diversas fontes energéticas, a energia eólica vem ganhando papel relevante no cenário global de energia limpa, por ter uma matriz renovável e com um extenso potencial ainda a ser explorado, tendo em vista que a força motriz é derivada dos ventos (BROWN, 2011; MUNDAY; BRISTOW; COWELL, 2011). Fadigas (2011) salienta que o Brasil é favorecido em boa qualidade de velocidade dos ventos, caracterizando-se por apresentar uma média de velocidade duas vezes maior que a mundial, e com uma variabilidade menor para áreas extensas. É importante evidenciar que a Região Nordeste dispõe, atualmente, do maior potencial disponível para a geração desse tipo de energia no país.

O Brasil assume papel de destaque no cenário mundial nesse tipo de energia, por apresentar importante participação das fontes renováveis em sua matriz energética, particularmente da energia eólica (BROWN, 2011). Em virtude da crescente preocupação ambiental com a geração de energia a partir de fontes renováveis, observa-se que, atualmente, em algumas regiões do Brasil, há um grau de implantação de empreendimentos de geração de energia eólica cada vez mais significativo ao nível espacial, a exemplo do Nordeste brasileiro, que teve a sua propagação do litoral para o interior (GORAYEB; BRANNSTROM, 2016).

Ao considerar o exposto, o presente estudo objetiva analisar, de forma integrada, os impactos socioambientais oriundos da implantação do Complexo Eólico Chapada do Piauí I no município de Marcolândia, estado do Piauí, na perspectiva de correlacionar as vantagens da geração de energia eólica, com os conflitos ambientais e sociais que são identificados e materializados in loco.

A partir desta perspectiva, almeja-se que a análise em pauta possa contribuir com outros estudos que se propõem a discutir a transformação da paisagem local a partir da perspectiva socioambiental, tendo como pano de fundo a implantação de tecnologias de exploração eólica como matriz energética.

\section{LOCALIZAÇÃO E CARACTERIZAÇÃO DA ÁREA DE ESTUDO}

O município de Marcolândia integra a Microrregião do Alto Médio Canindé e está localizado no sudeste piauiense, a 412 quilômetros da capital, Teresina. Sua população, 
segundo estimativa do IBGE para o ano de 2017, é de 8.342 habitantes (IBGE, 2017). Possui uma área territorial de 143,87 quilômetros quadrados e densidade demográfica de $54,30 \mathrm{hab} / \mathrm{km}^{2}$. Limita-se ao norte com os municípios de Caldeirão Grande do Piauí e Francisco Macedo/PI, ao sul com o município de Simões/PI, a oeste com os municípios de Padre Marcos/PI e Francisco Macedo/PI e, a leste, com o estado de Pernambuco (Figura 1).

Figura 1 - Mapa de localização do município de Marcolândia, Estado do Piauí

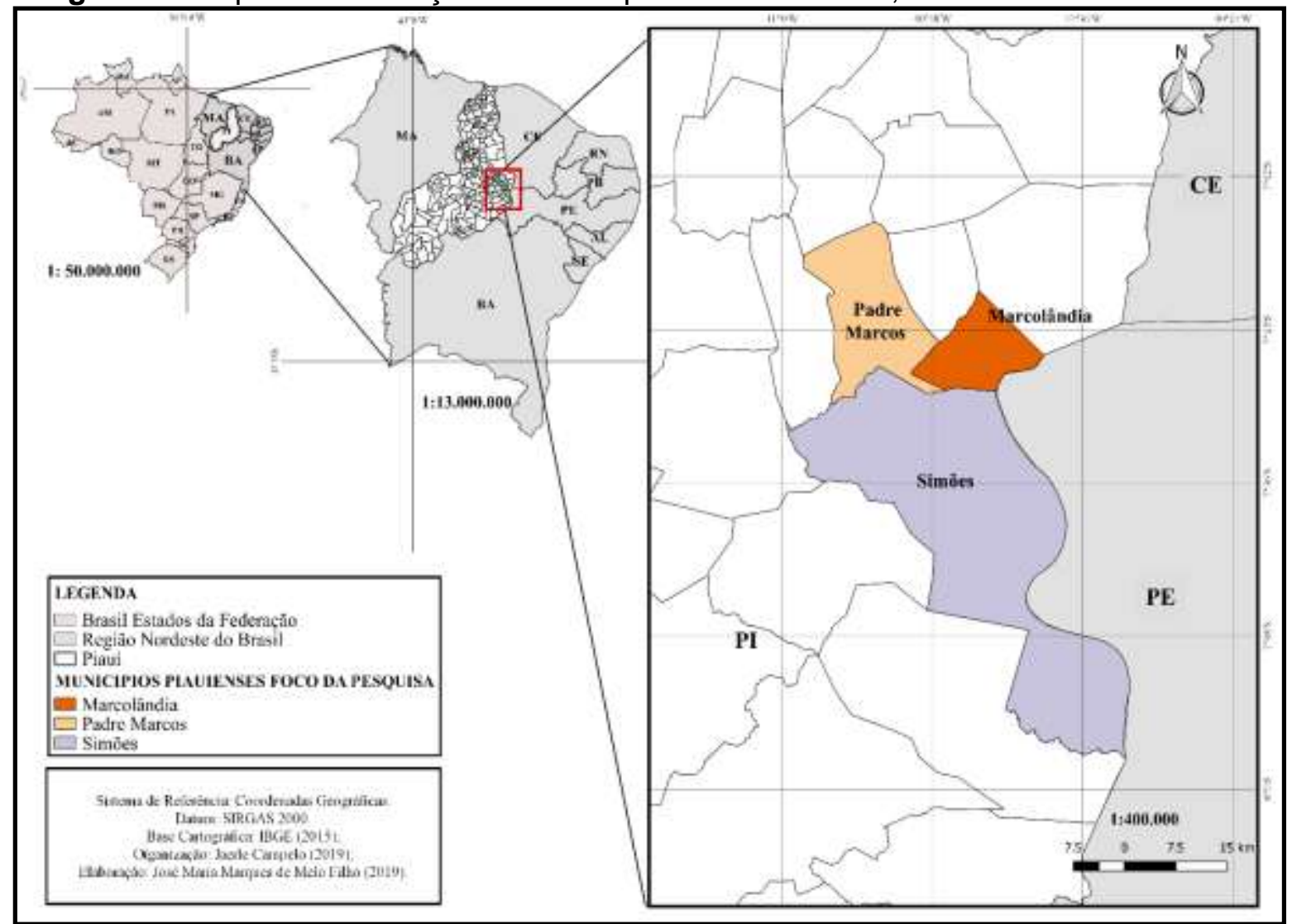

Elaborado por Melo Filho (2019).

Do ponto de vista hidrográfico, o município em pauta encontra-se inserido na Bacia Hidrográfica do Rio Parnaíba, especificamente na sub-bacia hidrográfica do Rio Canindé, apresentando uma morfologia predominantemente plana, tendo em vista a sua localização no rebordo ocidental da Chapada do Araripe. No que tange à fisionomia vegetal, a área está localizada no Bioma Caatinga, tendo em vista que o clima predominante é o semiárido.

No setor primário, a mandioca é o principal produto cultivado na região, sendo que a sua produção, em maior escala, tem como destino a comercialização no mercado regional. Não obstante, pode-se destacar também, em menor escala, o cultivo do milho, feijão e melancia (CÂMPELO, 2016).

No que se refere aos fatores socioeconômicos, de acordo com as informações disponibilizadas pelo IBGE (2010), o município apresenta um Produto Interno Bruto (PIB) de $\mathrm{R} \$ 40.240,00$ mil, sendo que a renda Per Capita é de $\mathrm{R} \$ 4.955,03$, mas com uma economia 
bem concentrada, e o IDHM é de 0,562. Deste modo, tal informação fornece subsídios para entender os impactos, principalmente, financeiros, ocasionados pela chegada dos aerogeradores no município.

Destaca-se que a área do parque eólico no município em questão (Complexo Eólico Chapada do Piauí I) abrange a porção piauiense da Bacia do Araripe, região que ganha destaque geomorfológico pela Chapada do Araripe, no trecho de divisa com o estado de Pernambuco.

De acordo com a ABEEólica (2016), o Complexo Chapada do Piauí I (Figura 2) possui, atualmente, 14 parques, com 115 torres instaladas, sendo 86 no município de Marcolândia/PI, 22 em Simões/PI e sete em Padre Marcos/PI, com potência total instalada de 205,1 MW, mas com área para expansão.

Figura 2 - Localização do Complexo Eólico Chapada do Piauí I

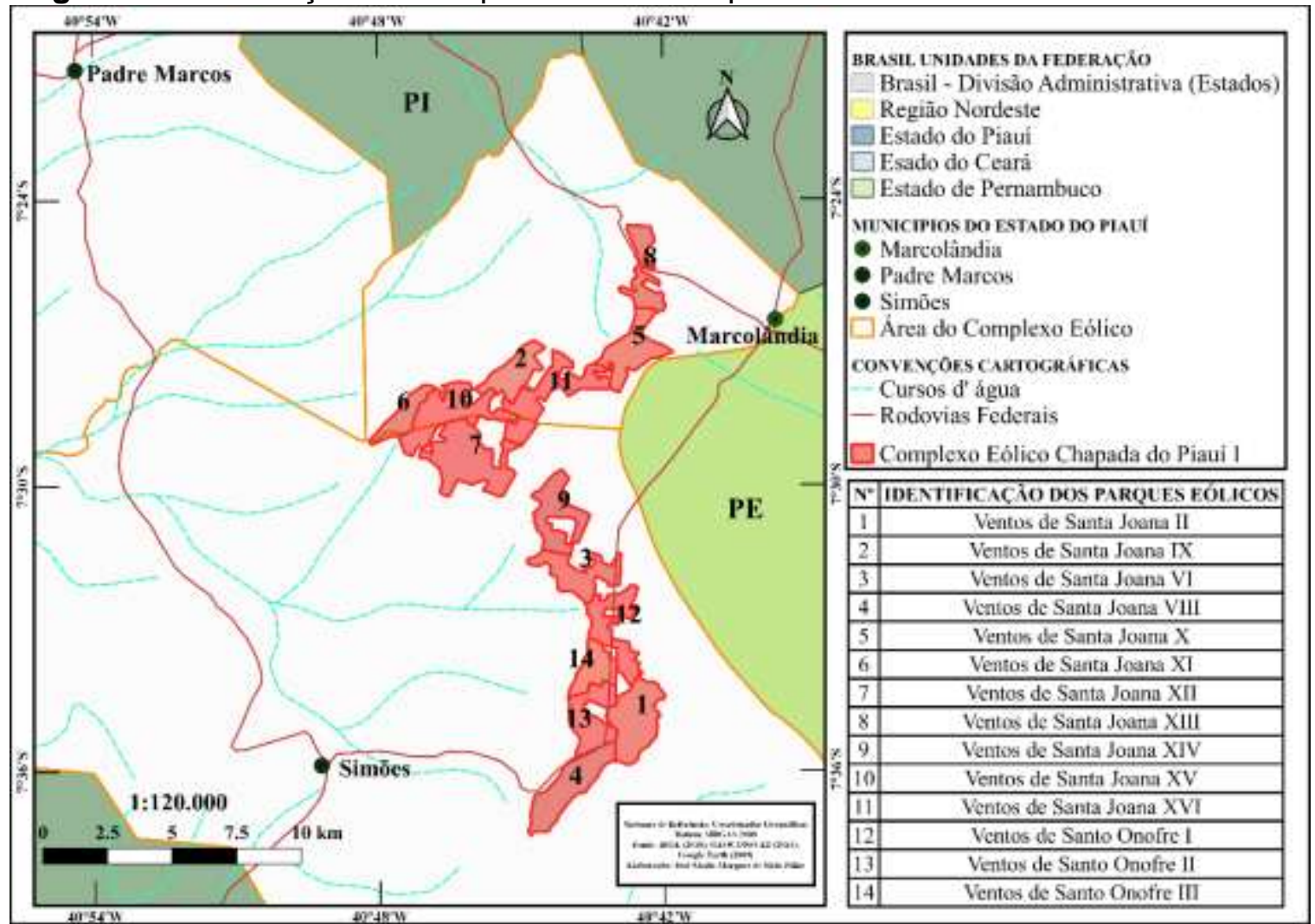

Elaborado por Melo Filho (2019).

Por outro lado, é notório diagnosticar um conjunto de impactos socioambientais decorrentes da implantação do parque eólico no município de Marcolândia/PI, o que tem causado mudanças na paisagem e nas atividades tradicionais, bem como na luta pela posse e registro das terras, em virtude do arrendamento de setores espaciais para a implantação dos aerogeradores. 
Diante do exposto, tal fato justifica a proposta do presente estudo no estado do Piauí e, particularmente, no município de Marcolândia, no intuito de analisar os impactos socioambientais provenientes do Complexo Eólico Chapada do Piauí I, considerando os cenários ambientais, os conflitos sociais e as vantagens econômicas frente à implantação dos aerogeradores nas localidades: Serra do Cícero Mundinho, Serra do Sebastião Silvestre e Cabeça da Ladeira.

\section{METODOLOGIA}

Do ponto de vista metodológico, a pesquisa contempla revisão bibliográfica e de campo (LAKATOS; MARCONI, 2010). Destaca-se que o estudo pode ser classificado como de obtenção de dados, podendo este ser por meio de documentação direta e/ou indireta. A pesquisa de campo faz parte da documentação direta, pois se constitui de levantamento no próprio local onde os fenômenos ocorrem.

Sobre os métodos elencados para obter respostas por intermédio do objetivo pretendido na pesquisa, empregaram-se tanto os dados qualitativos quanto os quantitativos. Deste modo, a pesquisa configura-se como exploratória e descritiva. Para tal, foram realizados trabalhos de campo, com conversa com os moradores da zona rural (no entorno das áreas onde foram instalados os parques eólicos) e urbana do município de Marcolândia, estado do Piauí.

Dessa forma, parte-se dos preceitos da análise documental, com leitura crítica e analítica do assunto em pauta. Os resultados almejados visam identificar os impactos socioambientais derivados da implantação do Complexo Eólico Chapada do Piauí I, tomando o município de Marcolândia/PI como unidade de estudo.

A difusão da produção da energia eólica em território piauiense, no litoral do estado, tem potencial eólico de aproximadamente 500MW em uma área de 20.000 hectares, abrangendo os municípios de Ilha Grande, Parnaíba, Luís Correia e Cajueiro da Praia. Por outro lado, a região do Planalto da Ibiapaba, na porção piauiense, tem potencial eólico estimado em 200MW, em uma área de 10.000 hectares, com destaque para os municípios de Assunção do Piauí, São Miguel do Tapuio e Buriti dos Montes. O potencial eólico da Chapada do Araripe é de $2.400 \mathrm{MW}$, onde estão localizados os municípios de Marcolândia (foco de estudo da análise), Caldeirão Grande, Padre Marcos, Simões, Curral Novo do Piauí, Paulistana e Betânia do Piauí (PIAUÍ, 2015).

Com relação à matriz eólica e ao recorte espacial adotado na pesquisa, destacam-se alguns fatores que contribuíram na escolha e delimitação da área que compreende o Complexo Eólico Chapada do Piauí I, tais como: 1) situação geográfica ideal, em ambiente contemplado por correntes eólicas regulares e dotada de velocidades significativas, em 
áreas situadas em superfície topograficamente plana e elevada da borda oeste da Chapada do Araripe; 2) disponibilidade de terrenos, que oferecem grandes áreas livres e com pouca variação altimétrica; 3) existência de infraestrutura básica na região de entorno para dar suporte à implantação e operação do empreendimento, sobretudo rodovias e 4) existência de levantamentos quanto ao potencial eólico da região (PIAUí, 2013).

A coleta de dados in loco (pesquisa de campo) foi realizada no Parque Eólico Ventos de Santa Joana XVI, sublinhando as localidades que sofreram influência direta com a implantação do empreendimento eólico no município de Marcolândia/PI, a saber: Serra do Cícero Mundinho, Serra do Sebastião Silvestre e Cabeça da Ladeira, servindo estas comunidades como área de amostragem no estudo (Figura 3).

Figura 3 - Localização das Comunidades no Parque Ventos de Santa Joana XVI

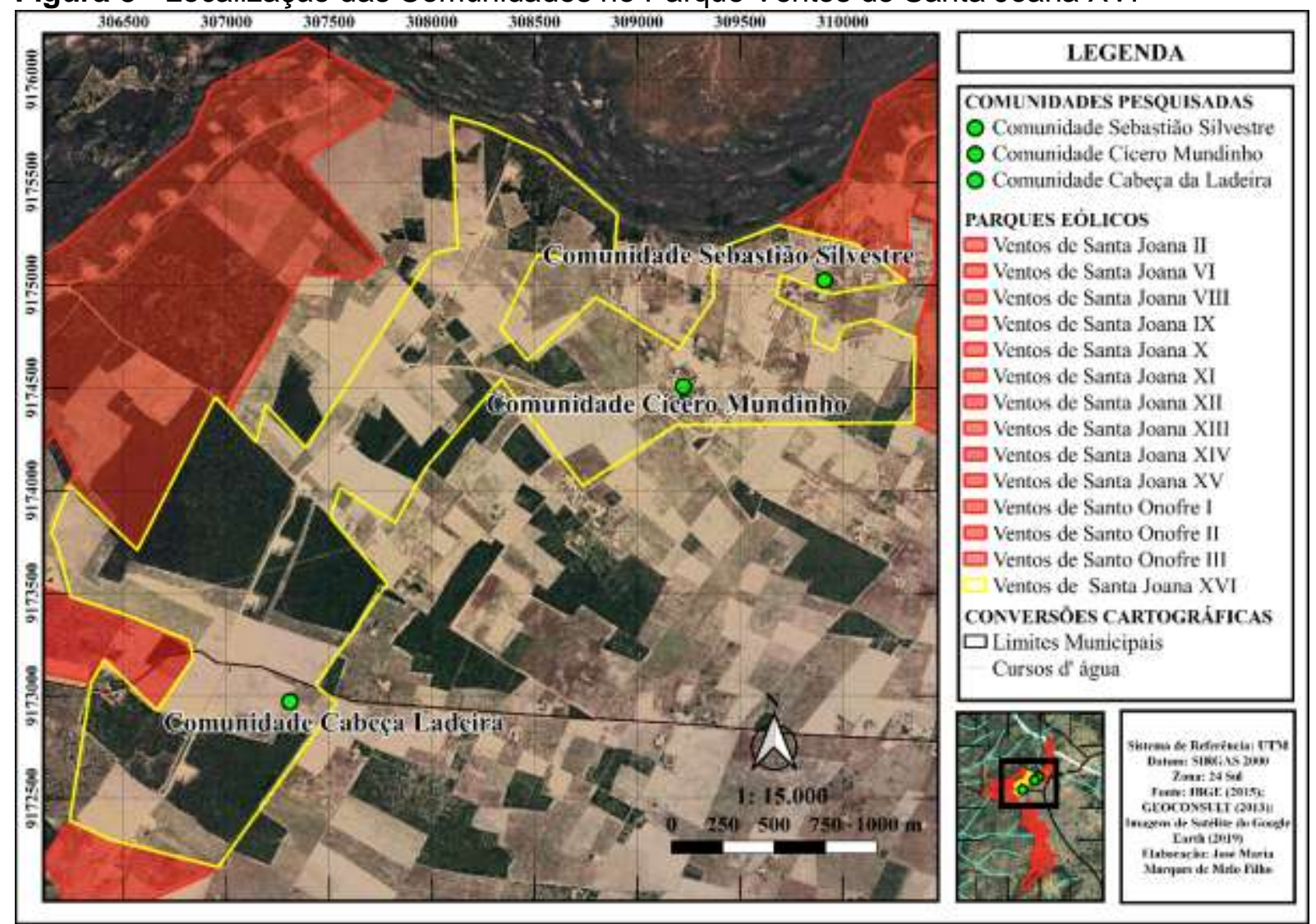

Elaborado por Melo Filho (2019).

Corrobora-se que além das comunidades mencionadas, foram colhidas informações na área urbana do município supracitado, com a finalidade de compreender o Complexo Eólico Chapada do Piauí I no cotidiano dos moradores, considerando os impactos socioambientais derivados. 


\section{ENERGIA EÓLICA E OS IMPACTOS SOCIOAMBIENTAIS}

Ao considerar que a energia eólica vem ganhando destaque no setor elétrico mundial e nacional nos últimos anos, corrobora-se que a mesma transforma energia cinética em elétrica através da força dos ventos. Por ser uma atividade dita como sustentável, do ponto de vista de sua geração, a energia eólica é categorizada como limpa ao meio ambiente, constituindo um mecanismo que agrega os preceitos dos parâmetros social, econômico e ambiental na matriz geradora (FADIGAS, 2011; JABER, 2013; RUIZ; SERRANO, 2006).

No Piauí, o incremento da produção de energia eólica tende a proporcionar um maior desenvolvimento para o estado, caso esta política seja efetivada de forma adequada e respeitando os preceitos do desenvolvimento sustentável, pois o mesmo possui uma expressiva potencialidade para a geração desse tipo de energia, devido a sua situação geográfica, tanto no litoral, quanto em setores do interior.

O mosaico de imagens da Figura 4 ilustra a implantação, em diferentes pontos, dos aerogeradores no município de Marcolândia, onde está localizado o Complexo Eólico Chapada do Piauí l.

Vale salientar que na instalação de uma torre para a produção de energia eólica, estes equipamentos ocupam uma parcela do terreno, sendo que o restante da propriedade arrendada pode ser utilizado pelos moradores no desenvolvimento das atividades agropecuárias, com destaque para o cultivo de mandioca e criação de animais.

A compatibilidade entre a presença e o funcionamento de um parque eólico com outros tipos de atividades é bem perceptível nas três comunidades que integraram a pesquisa (Cícero Mundinho; Sebastião Silvestre e Cabeça da Ladeira), uma vez que não houve a desapropriação das terras dos moradores com a instalação do Complexo Eólico Chapada do Piauí I, mas sim o arrendamento dos terrenos para a instalação das torres, como pode ser visualizado na Figura 5. Portanto, foi constatada in loco a continuidade das atividades primárias (agricultura e pecuária) em conjunto com a geração de energia eólica.

Conforme constatado em campo, os moradores beneficiados com o arrendamento das propriedades relataram que a implantação dos aerogeradores trouxe benefícios para as famílias, pois com a locação dos terrenos passaram a receber um montante de $R \$ 1.500,00$ (mil e quinhentos reais) mensais por cada torre instalada em sua propriedade.

De acordo com os arrendatários, o valor da locação de suas terras veio complementar a renda das famílias e, ainda, proporcionar a continuidade da agricultura familiar, tendo em vista que o restante do terreno pode ser utilizado para diversos fins. Por outro lado, corrobora-se que existem grupos empresariais na região, conhecidos como "corretores dos ventos", particularmente de Picos/PI e de Araripina/PE, sondando a compra e/ou a desapropriação das terras das comunidades tradicionais. 
Figura 4 - Mosaico de imagens apresentado a implantação do Complexo Eólico

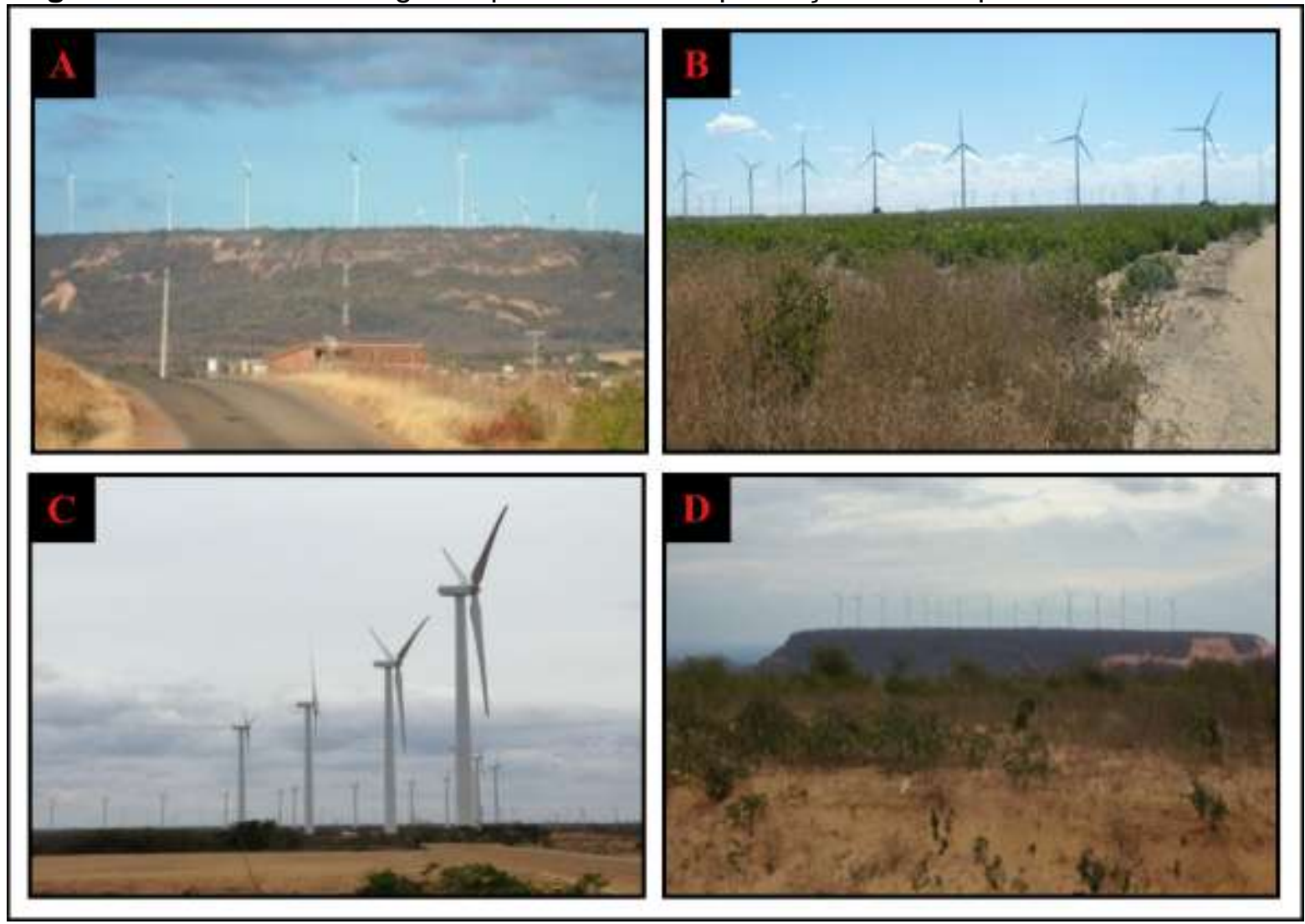

Fonte: Campêlo (2018).

A - Imagem dos aerogeradores próximo a BR - 316, rodovia de acesso ao município de Marcolândia - PI; B - Visão dos aerogeradores próximo de áreas utilizadas para a agricultura; C A imagem ilustra os aerogeradores localizados as margens da estrada de "chão" em direção às comunidades da zona rural do município em questão; D - Visão dos aerogeradores localizados sob a chapada.

Dessa forma, é nítido o interesse, atualmente, das terras que foram historicamente ocupadas pelas populações tradicionais, mas que em virtude dos fatores econômicos da geração de energia eólica (arrendamento das terras) ascenderam às especulações por essas porções territoriais do semiárido piauiense, que foram durante séculos deixadas as margens do desenvolvimento do estado.

A inserção de projetos de energias renováveis em áreas rurais, especialmente em setores que carecem de desenvolvimento econômico, a exemplo da localização do complexo eólico do município de Marcolândia/PI, como é o caso, por exemplo, da Comunidade Cícero Mundinho (Figura 6), causa inúmeros impactos para a comunidade local.

Conforme Munday, Bristow e Cowell (2011), ao avaliarem os impactos da instalação de parques eólicos no País de Gales, no Reino Unido, sua implantação ocorre, principalmente, em áreas rurais com desafios específicos de desenvolvimento econômico, com a finalidade de fomentar o desenvolvimento local. Ao fazermos um paralelo em relação 
as comunidades pesquisadas, resguardadas as devidas proporções, a implantação do Complexo Eólico Chapada do Piauí I tem como princípio fundante promover o desenvolvimento local da região.

Figura 5 - Cultivo agrícola de mandioca associado à geração de energia eólica

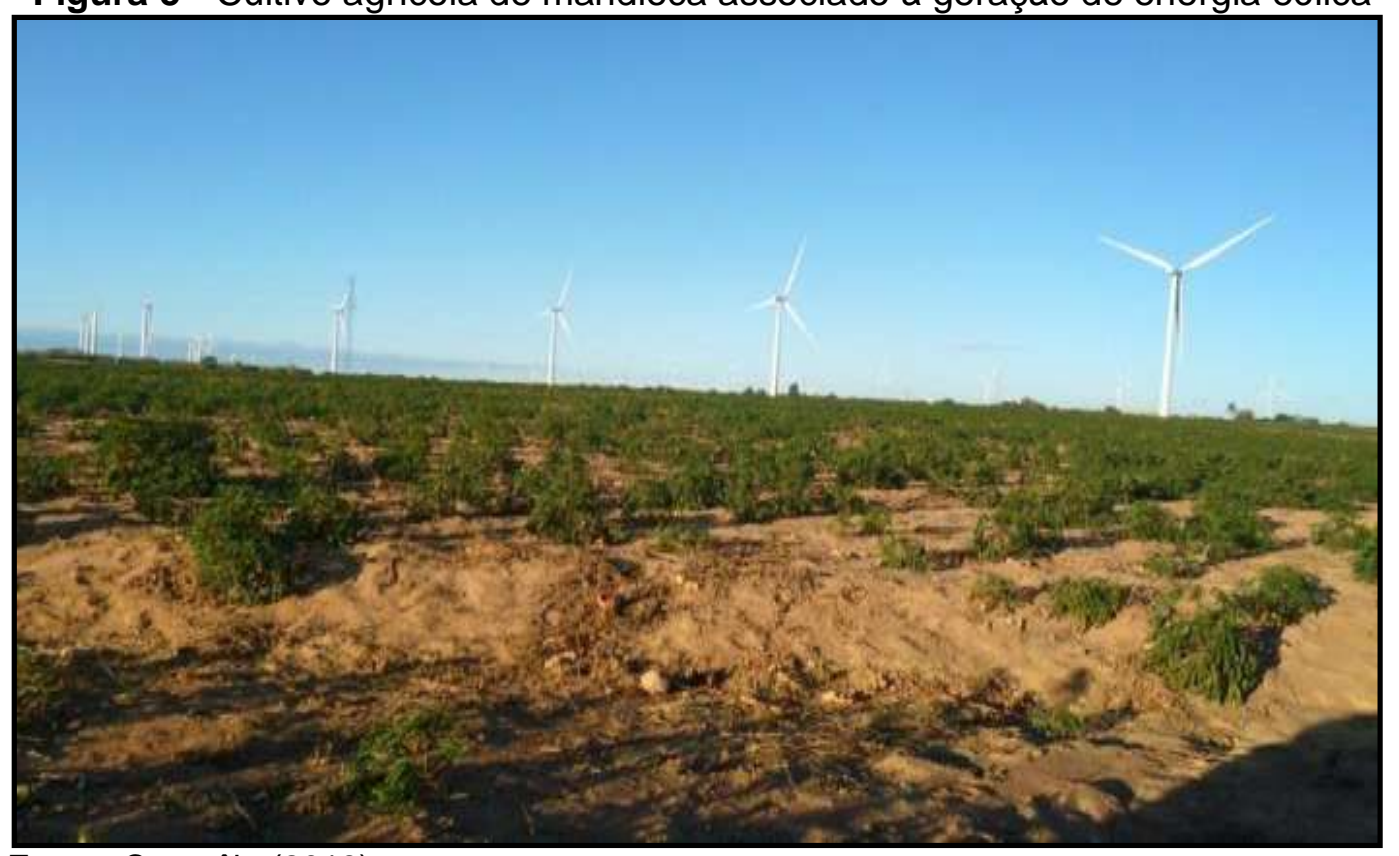

Fonte: Campêlo (2018).

Figura 6 - Comunidade Cícero Mundinho, em Marcolândia - PI

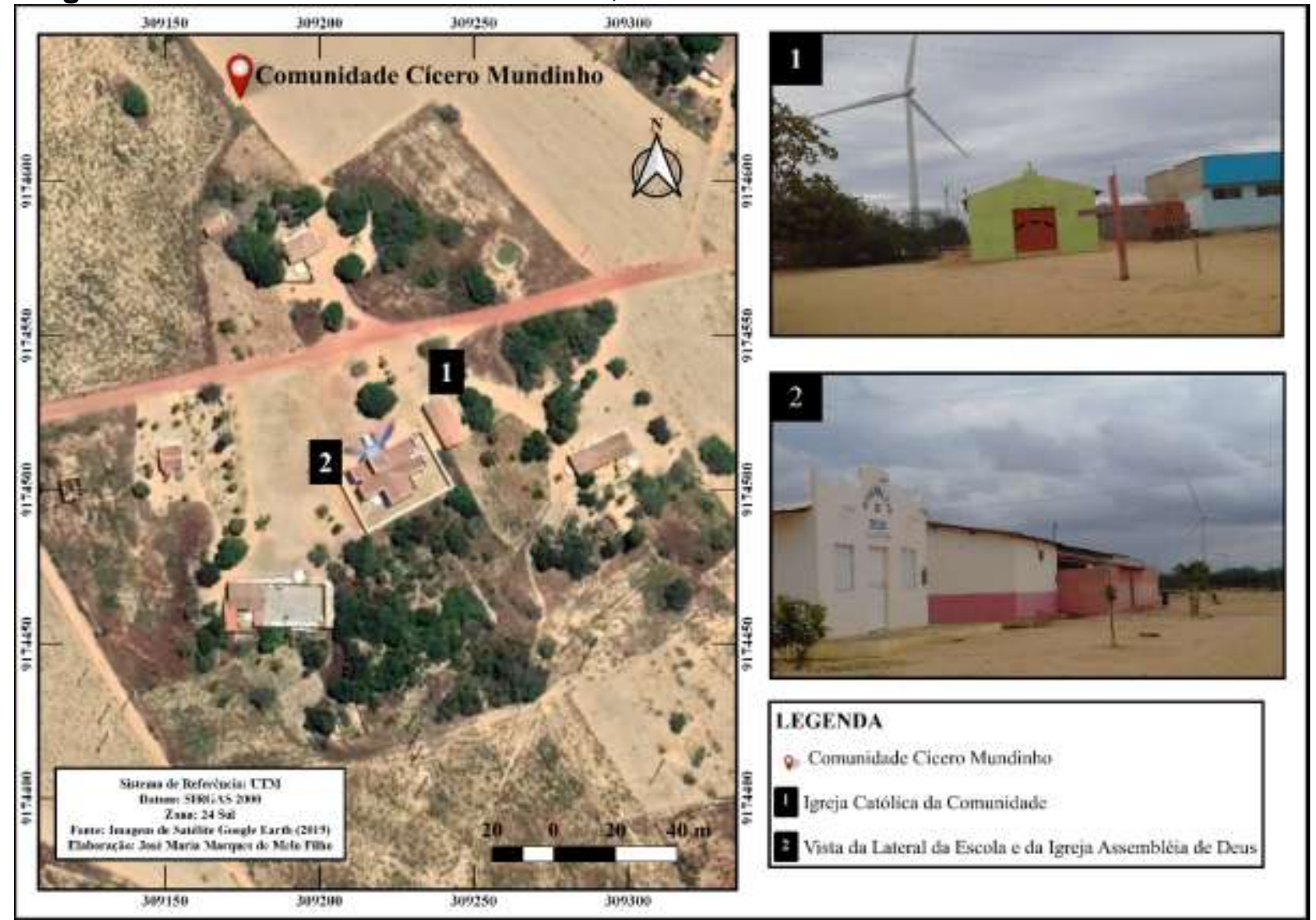

Elaborado por Melo Filho (2019). 
Entretanto, surgem questões importantes relacionadas à capacidade das comunidades locais adaptarem-se ao projeto do Complexo Eólico, bem como a identificação das formas de captação de recursos para fomentar o desenvolvimento local e de que forma ocorrerá a integração das comunidades com as atividades desenvolvidas nas fases de implantação do complexo.

Referente aos impactos ambientais, a Resolução n‥ 01/86 do (CONAMA) Conselho Nacional do Meio Ambiente (1986), em seu artigo 1ํㅡ, assinala que o mesmo é caracterizado como qualquer alteração das propriedades físicas, químicas e biológicas do meio ambiente, causada por qualquer forma de matéria ou energia resultante das atividades antrópicas que afetam direta ou indiretamente: i) a saúde, a segurança e o bem-estar da população; ii) as atividades sociais e econômicas; iii) a biota (conjunto de plantas e animais de uma determinada área); iv) as condições estéticas e sanitárias do meio ambiente e v) a qualidade dos recursos ambientais.

Ao correlacionar os impactos ambientais aos empreendimentos de geração de energia eólica, percebe-se a proporção dos impactos dentro dessa perspectiva (Figura 7). Portanto, constata-se que o percentual sobre a fauna é o mais atingido, com $25 \%$, seguido do impacto paisagístico, com 21\%. Em contrapartida, de acordo com esse estudo, os impactos referentes à interferência eletromagnética e socioeconômicos são mínimos, conforme aponta Empresa de Pesquisa Energética (2009).

Figura 7 - Percentual dos impactos associados à geração de energia eólica

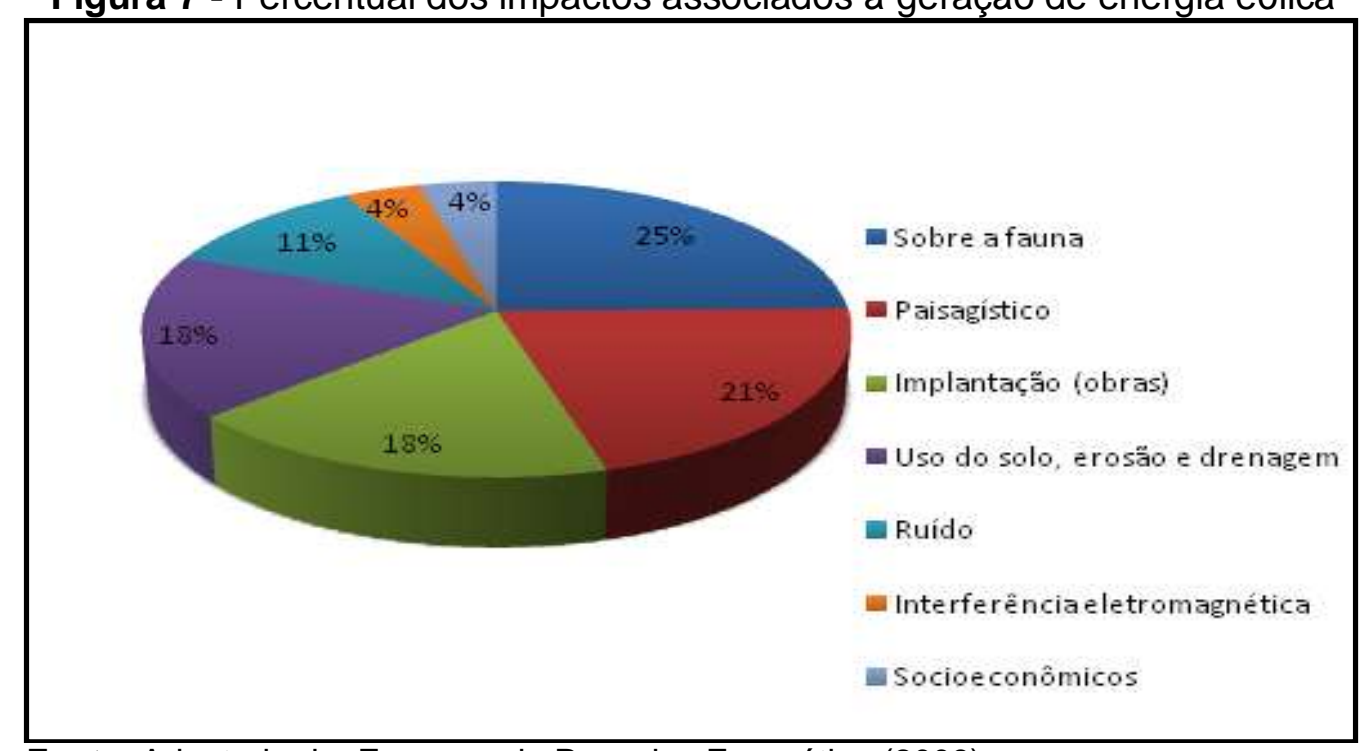

Fonte: Adaptado de: Empresa de Pesquisa Energética (2009).

Ao considerar os impactos socioambientais oriundos da implantação do Complexo Eólico Chapada do Piauí I no município de Marcolândia, estado do Piauí, elencam-se 
alguns, com base nas informações e análises colhidas in loco, a saber: 1) perda da cobertura vegetal, causada pela abertura de vias de acesso, montagem das plataformas dos aerogeradores e das áreas das subestações; 2) a supressão vegetal desencadeia a perda de habitats, ocasionando a redução de populações da fauna e da flora e, consequentemente, da biodiversidade da área; 3) perda da umidade e de nutrientes do solo, oriundos dos desmatamentos; 4) ruído dos rotores, em virtude da proximidade com as residências, como demonstrado na Figura 8; 5) impacto visual; e 6) questão fundiária a respeito da posse e registro das terras.

Figura 8 - Presença de aerogerador no quintal de uma residência na comunidade Cabeça da Ladeira na zona rural de Marcolândia, PI

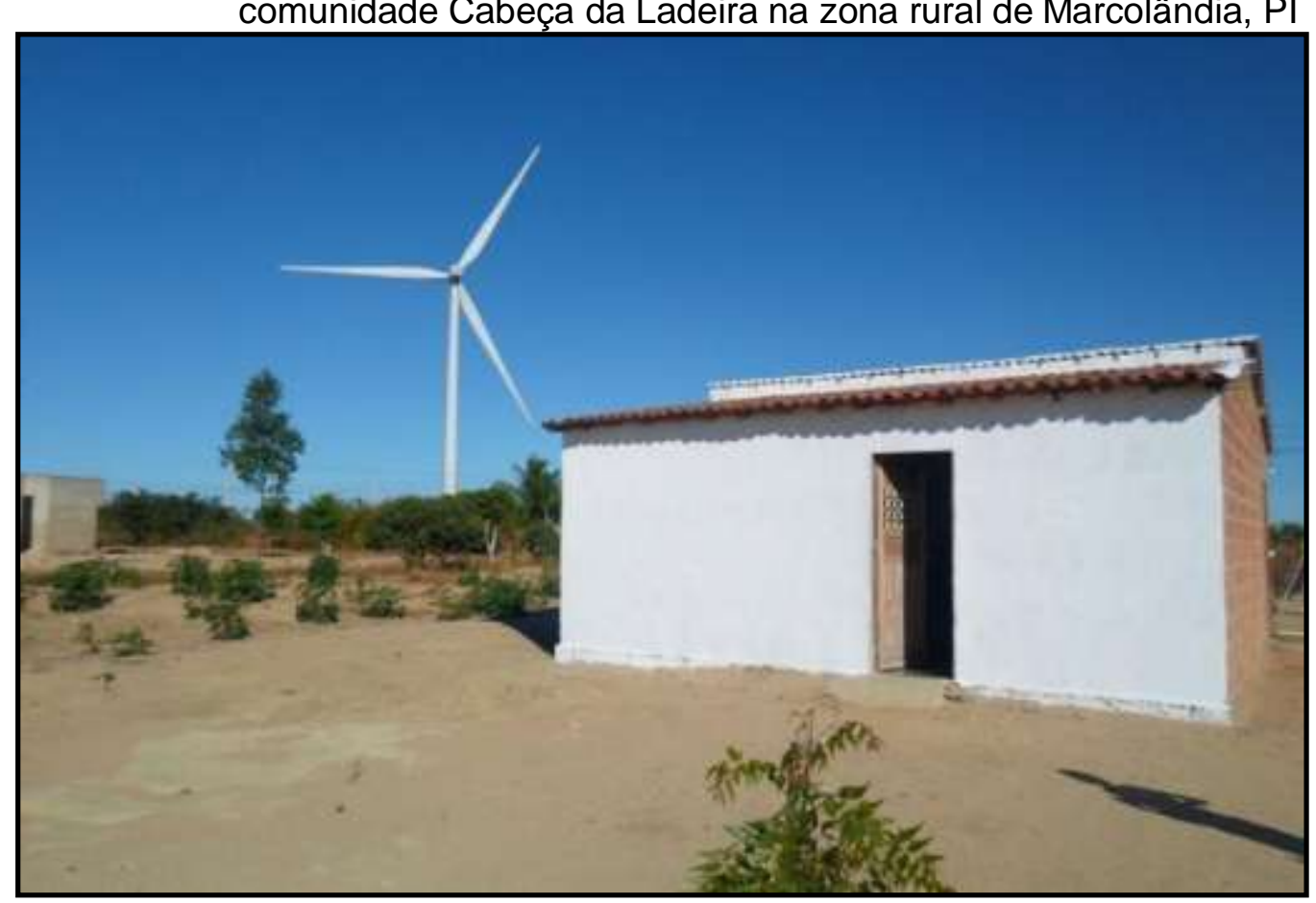

Fonte: Campêlo (2017).

Reafirmando essa perspectiva, Ruiz; Serrano (2006) salientam que durante o processo de implantação de um complexo eólico, em razão de sua ocupação física destinada para a construção de edifícios auxiliares, estradas de acesso, limpeza e remoção da cobertura edáfica, os potenciais impactos sobre a vegetação derivados de sua instalação são: remoção da cobertura vegetal; degradação de comunidades vegetais por pressão antrópica e perda da vegetação.

Outro impacto a ser destacado são os ocasionados na fauna e avifauna, devido à instalação dos aerogeradores em complexos eólicos (JABER, 2013). De acordo com o relatório de monitoramento e gestão ambiental da fase de operação do Complexo Eólico Chapada do Piauí I, realizado pela MRS Estudos Ambientais, durante as vistorias em 
campo, foram encontradas carcaças de morcegos e aves nas bases dos aerogeradores, retratando um impacto visível e notório na paisagem (MRS AMBIENTAL, 2016).

Com relação ao estudo da paisagem, após a instalação de aerogeradores no município de Marcolândia/PI, buscou-se, a partir das evidências expostas, compreender a concepção dos entrevistados sobre a paisagem e seus elementos constituintes, associados, sobretudo, às formas e funções. Neste contexto, tentou-se apreender como a comunidade entende e visualiza a transformação da paisagem, antes e após a instalação dos aerogeradores.

Os resultados dos trabalhos de campo evidenciaram que a tão propagada prosperidade econômica oriunda do setor de energia eólica, nesta região, vem causando tensões territoriais, por outro lado, conseguiu trazer benefícios para as famílias contempladas com o arrendamento de suas terras.

Neste sentido, é importante evidenciar que os impactos socioambientais referentes à geração de energia eólica ocorreram de forma positiva e negativa no município de Marcolândia/PI. Positiva, no momento em que a população passa a agregar valor com o arrendamento dos terrenos, obtendo deste modo uma visível melhoria nas condições financeiras após a instalação do empreendimento eólico, que contribui com o desenvolvimento socioeconômico da região e do estado. Por outro lado, é considerado como impactos negativos as percepções adversas à paisagem com os aerogeradores, bem como os ruídos e os desmatamentos.

\section{CONCLUSÃO}

A geração de energia eólica vem se destacando mundialmente e, particularmente, no estado do Piauí, Região Nordeste do Brasil. É uma fonte energética de extrema importância no intuito de assegurar um futuro energético sustentável, desde que sejam respeitados os preceitos da sustentabilidade do desenvolvimento econômico.

No que diz respeito à qualidade do vento, os melhores para a geração de energia eólica no Brasil estão na Região Nordeste, onde estes são constantes, fazendo com que a região atinja recordes referentes à geração desta matriz energética. Neste contexto, merece destaque a região que contempla a borda oeste da Chapada do Araripe, com ênfase ao município de Marcolândia, estado do Piauí.

Verificou-se a concomitância entre a geração de energia eólica e as atividades pessoais desenvolvidas nas comunidades rurais onde se localiza o Complexo Eólico Chapada do Piauí I. Isso é possível porque os aerogeradores, após serem instalados, ocupam uma pequena área, proporcionando a continuidade das atividades agropecuárias 
(cultivo de mandioca e criação de animais) pelos proprietários das terras, tendo em vista que houve somente o arrendamento, e não a desapropriação.

Em Marcolândia/PI, os impactos positivos mais significativos estão relacionados à melhoria nas condições financeiras das famílias contempladas com o arrendamento de suas terras. Por outro lado, os impactos negativos mais evidentes estão na área ambiental, com a perda da avifauna e pelas mudanças na paisagem. Dessa forma, são nítidos os seguintes impactos socioambientais na área em análise: supressão vegetal; perda da biodiversidade; mudanças nas características dos solos; ruído dos rotores, e impacto visual dos aerogeradores.

\section{REFERÊNCIAS}

ABEEólica. Associação Brasileira de Energia Eólica. Números do setor. 2016. Disponível em: http://www.portalabeeolica.org.br. Acesso em: 31 jan. 2019.

BROWN, K. B. Wind power in northeastern Brazil: Local burdens, regional benefits and growing opposition. Climate and Development, Berkeley, CA, v. 3, n. 4, p. 344-360, oct. 2011.

CAMPÊLO, J. R. Energias renováveis e sustentabilidade: um olhar geográfico para o parque eólico de Marcolândia, Estado do Piauí, Brasil. REGNE: Revista de Geociências do Nordeste, Natal, RN, v. 2, p. 904-912, 2016. Número Especial.

CAMPÊLO, J. R.; LOVATE, T. B.; OLIVEIRA, E. R.; ALBUQUERQUE, E. L. S. Complexo Eólico Chapada do Piauí I: uma análise para o município de Marcolândia (Piauí, Brasil).

Revista GeoUECE, Fortaleza, CE, v. 6, n. 10, p. 42-58, jan./jun. 2017.

CONSELHO NACIONAL DO MEIO AMBIENTE. Resolução Conama no 1 de 17/01/1986. Dispõe sobre critérios básicos e diretrizes gerais para a avaliação de impacto ambiental. Brasília: CONAMA, 1986. Disponível em:

http://www.mma.gov.br/port/conama/legislacao/CONAMA_RES_CONS_1986_001.pdf. Acesso em: 10 set. 2017.

EMPRESA DE PESQUISA ENERGÉTICA. Balanço energético nacional. Brasília: EPE, 2009.

FADIGAS, E. F. A. Energia eólica. Barueri, SP: Manole, 2011. (Série sustentabilidade).

FERREIRA, R. M. R. Las implicaciones ambientales del proceso de implantación de los parques eólicos: la situación en Galicia. Revista Gallega de Economía, Santiago de Compostela, v. 20, n. 1, p. 1-20, 2011.

GORAYEB, A.; BRANNSTROM, C. Caminhos para uma gestão participativa dos recursos energéticos de matriz renovável (parques eólicos) no nordeste do Brasil. Mercator, Fortaleza, CE, v. 15, n. 1, p. 101-115, jan./mar. 2016.

IBGE. Censo demográfico de 2010. 2010. Disponível em: www.sidra.ibge.gov.br. Acesso em: 22 jul. 2018.

IBGE. Cidades. 2017. Disponível em: http://www.cidades.ibge.gov.br. Acesso em: 22 jul. 2018.

JABER, S. Environmental impacts of wind energy. Journal of Clean Energy Technologies, Bagdá, v. 1, n. 3, p. $251-254$, jul. 2013. 
LAKATOS, E. M.; MARCONI, M. A. Metodologia do trabalho científico. São Paulo: Atlas, 2010.

LOPEZ, R. A. Energia eólica. 2. ed. São Paulo: Artliber, 2012.

MRS AMBIENTAL. Estudos Ambientais. Relatório de execução, monitoramento e gestão ambiental da fase de operação do Complexo Eólico Chapada do Piauí I. BRASÍLIA, DF: MRS, 2016.

MUNDAY, M.; BRISTOW, G.; COWELL, R. Wind farms in rural areas: how far do community benefits from wind farms represent a local economic development opportunity? Journal of Rural Studies, Cardiff, UK, v. 27, n. 1, p. 1-12, Jan. 2011.

PIAUÍ. Assembleia Legislativa do Estado. Relatório da visita dos parlamentares piauienses ao Complexo Eólico Chapada do Piauí. Teresina: ALEPI, 2015.

PIAUÍ. Secretaria do Meio Ambiente e Recursos Hídricos do Estado. Estudo de impacto ambiental (EIA). Teresina: Complexo Eólico Chapada do Piauí, 2013. v. 1, T. b.

RUIZ, J. M.; SERRANO, M. L. T. Identificación de impactos ambientales significativos en la implantación de parques eólicos: un ejemplo en el municipio de Jumilla (Murcia).

Investigaciones Geográficas (Esp), San Vicente del Raspeig, ESP, n. 41, p. 145 -154, 2006.

SIMAS, M. S.; PACCA, S. Energia eólica, geração de empregos e desenvolvimento sustentável. Estudos Avançados, São Paulo, v. 27, n. 77, p. 99-115, abr. 2013.

Recebido: agosto de 2019. Aceito: dezembro de 2019. 